\title{
Recovery of Function Following Simultaneous and Serial Telencephalon Ablation in the Teleost, Macropodus opercularis ${ }^{1}$
}

\author{
JefFrey Kassel and Roger E. Davis
}

\begin{abstract}
The Mental Health Research Institute and The Neuroscience Laboratory, The University of Michigan, Ann Arbor, Michigan 48109
\end{abstract}

\begin{abstract}
Previous investigations in male Macropodus showed that simultaneous bilateral removal of the telencephalon results in decreased sexual and nest-building behavior. The current investigation was to determine whether serial unilateral ablation of the telencephalic hemispheres, increased recovery time following simultaneous ablation, or prior spawning experience can produce savings in reproductive behavior. Preoperative sexual experience did not alter the behavioral effects of telencephalon ablation. All components of reproductive behavior were decreased following serial or simultaneous ablation of the telencephalon, but none were eliminated. When simultaneous ablation males were allowed to recover for a period of time equal to that following the second operation of the serial ablation, they showed less sexual behavior than the serial ablation males. When the recovery time was equal to that following the first operation of the serial ablation, the simultaneous and serial ablation males showed no significant differences in reproductive behavior. The results indicate that removal of one lobe of the telencephalon initiates alterations in nontelencephalic structures which result in increased savings in sexual behavior following removal of the second hemisphere. Similar neural alterations may be responsible for the recovery of function following simultaneous bilateral ablation of the telencephalon.
\end{abstract}

Serial lesions of the central nervous system may result in less behavioral impairment than a single lesion which destroys a similar amount of nervous tissue. Serial lesions in different areas of the mammalian brain often result in sparing of sensory, motor, or associational function (review: Finger et al., 1973). The physiological basis for the sparing of behavioral functions by serial lesions is poorly understood.

Whether complex species-typical behaviors are spared by serial lesions has not been extensively investigated. Rowe and Smith (1973) reported that, while simultaneous ablation of the olfactory bulbs eliminated mating behavior in male mice, successive unilateral bulbectomies, 30 days apart, produced no behavioral deficit. On the other hand, Winans and Powers

1 We thank Janet Peugh for her assistance with the behavioral observations. 
(1974) found that serial lesions do not prevent the loss of mating behavior in bulbectomized male hamsters. We examined the effects of serial ablation of the telencephalic hemispheres on reproductive behavior in the teleost, Macropodus opercularis. Simultaneous bilateral telencephalon ablation produces a drastic reduction in nest-building, courtship, and spawning behaviors in male Macropodus (Davis et al., 1976a; Kassel et al., 1976), although components of reproductive behavior occasionally occur (Schwagmeyer et al., 1977).

Individual sexual experience is another variable which might determine the effect of a brain lesion on reproductive behavior. To examine this possibility, Macropodus males were spawned prior to simultaneous removal of both lobes of the telencephalon and prior to removal of the remaining lobe in a serial lesion procedure.

\section{METHODS}

Subjects. Thirty-eight adult male Macropodus opercularis (mean body length, $5.2 \mathrm{~cm}$, and weight, $4.1 \mathrm{~g}$ ) were obtained from domesticated stocks in Florida. Prior to the experiment, fish were kept in bisexual groups in 190-liter tanks. During the experiment, males were housed in 9-liter isolation tanks between spawning trials. While the previous sexual experience of the males was unknown, commercial and laboratory storage tanks are generally incompatible with reproduction in Macropodus. Diet, water, temperature, and light cycle were maintained as previously described (Davis et al., 1976a).

Experimental design. Two groups of males which were administered a simultaneous bilateral telencephalon ablation were given 5-day spawning trials, 2 and 4 weeks following the operation. One of these groups consisted of eight males which were spawned 3 weeks prior to the ablation; the other group of six males had no known spawning experience. Another two groups of eight males were administered serial unilateral telencephalon ablations 5 weeks apart. One of these groups was spawned 3 weeks prior to the second unilateral ablation; the other group of males had no known preoperative spawning experience. The serial ablation groups received two 5-day spawning trials beginning 2 and 4 weeks following the second operation.

Increased reproductive behavior in serial ablated males might reflect recovery processes which are initiated following the first unilateral ablation, 7 weeks prior to the spawning trial. Therefore, an additional group of eight males with no known spawning experience was administered two spawning trials beginning 7 and 9 weeks following simultaneous ablation.

Surgery. Simultaneous bilateral telencephalon ablation was performed as previously described (Davis et al., 1976a). In the serial ablation procedure, a Ziegler knife was passed between the telencephalic lobes, severing 
the anterior commissure (AC) and the commissure of the dorsal telencephalon (DMc) (Fig. 1). One lobe was then aspirated along with the attached olfactory bulb. The remaining lobe and olfactory bulb were removed by aspiration 5 weeks later.

Spawning trial. The male was placed in a 38-liter aquarium with a ripe adult female which had 1-day of residence. Water temperature was 25$26^{\circ} \mathrm{C}$. The male's behavior was observed twice daily for $10 \mathrm{~min}$ between 1000 and $1200 \mathrm{hr}$ and between 1600 and $1800 \mathrm{hr}$. If prespawning behavior was seen during the regularly scheduled observation period, additional observations were made during the afternoon and evening so that all spawnings were watched.

The following behavior patterns of the male were recorded as previously described (Davis and Kassel, 1975; Schwagmeyer et al., 1976): approach, lateral display, frontal display, quiver, chase, attack, bubble, curve, and clasp. Curve and clasp immediately precede spawning. The male's body curves laterally and then clasps the female. In a clasp, the male's head and caudal fin wrap around the anterior half of the female's body so that their urogenital pores are juxtaposed. The male then inverts the female beneath the foam nest. Gametes may or may not be released at this point. A clasp was recorded when the male inverted the female. Spawning was determined to have occurred when the female released eggs while being clasped by the male.

The frequency of the behavioral units was registered with a manual keyboard connected to a digital counter. The durations of bubble bouts were recorded on a running time meter. The shape and approximate surface dimensions of a foam nest and the presence of nests built by the female were noted. Males which spawned prior to the end of the 5-day trial were returned to the isolation tank or sacrificed preparatory to brain histology. Following the final spawning trial, the male was killed in ice water, and the brain was examined histologically as previously described (Davis et al., 1976a).

\section{RESULTS}

Approximately half of the males in the serial ablation groups showed curve and clasp in one or both spawning trials (Table 1). In contrast, in the groups which received a simultaneous ablation 2 weeks prior to spawning, only two males were seen to clasp. Clasp was performed by a higher percentage of serial ablation males than the simultaneous ablation males which were spawned 2 weeks postoperatively $\left(\chi^{2}=4.98, P<0.03\right)$. The probabilities of occurrence of bubble and curve were not altered by serial ablation. The simultaneous ablation males which were allowed to recover for 7 weeks prior to the first spawning trial showed probabilities of sexual behavior and of bubble which were not significantly different from those 

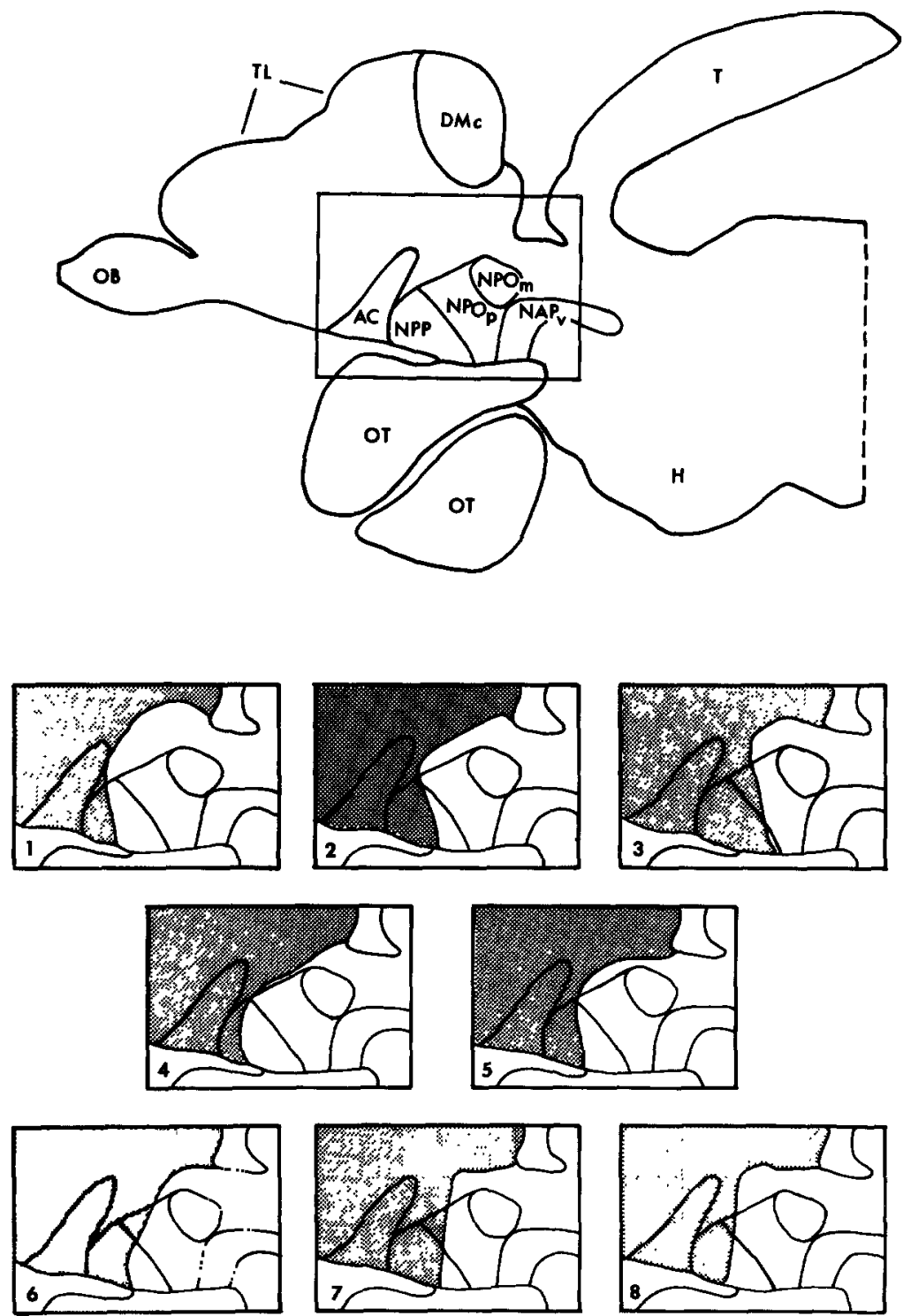

FIG. 1. The upper diagram shows a vertical longitudinal section of the brain of Macropodus. In the lower diagrams, the variation in the extent to which the telencephalon ablation invaded the preoptic nucleus is shown for the eight males in the 7 -week recovery group. The other groups of males showed similar variation. The stippled area represents ablated tissue. The brains are numbered in order of decreasing behavioral impairment: (1) no sexual or parental behavior: ( 2 and 3 ) bubble only; (4) bubble and curve: ( 5 and 6 ) bubble, curve, and clasp; ( 7 and 8 ) bubble, curve, clasp, and spawn. The behavioral effect of the ablations did not correspond to the amount of preoptic tissue removed. Abbreviations: AC, anterior commissure: DMc, area dorsalis telencephali pars medialıs commissuralis; $H$, hypothalamus: NAPv, nucleus anterioris periventricularis; NPOm, nucleus preopticus pars magnocellularis; NPOp, nucleus preopticus pars parvocellularis; NPP, nucleus preopticus periventricularis; $\mathrm{OB}$, olfactory bulb; OT, optic tract; T, optic tectum; TL, telencephalon. 
TABLE 1

Percentage of Males Which Performed the Various Reproductive

Behaviors in Either of the Two Spawning Trials

\begin{tabular}{|c|c|c|c|c|c|}
\hline \multirow[t]{2}{*}{ Group } & \multirow[t]{2}{*}{$N$} & \multicolumn{4}{|c|}{ Behavior } \\
\hline & & Bubble & Curve & Clasp & Spawn \\
\hline \multicolumn{6}{|l|}{ Simultaneous } \\
\hline $\begin{array}{l}\text { Not spawned } \\
\text { (2-week recovery) }\end{array}$ & 6 & 100 & 50 & 17 & 17 \\
\hline $\begin{array}{l}\text { Spawned }{ }^{a} \\
\text { (2-week recovery) }\end{array}$ & 8 & 75 & 75 & 12 & 12 \\
\hline \multicolumn{6}{|l|}{ Serial } \\
\hline $\begin{array}{l}\text { Not spawned } \\
(2 \text {-week recovery })^{b}\end{array}$ & 8 & 100 & 100 & 62 & 38 \\
\hline $\begin{array}{l}\text { Spawned }{ }^{c} \\
(2 \text {-week recovery })^{b}\end{array}$ & 8 & 75 & 75 & 50 & 25 \\
\hline \multicolumn{6}{|l|}{ Simultaneous } \\
\hline (7-week recovery) & 8 & 88 & 62 & 50 & 25 \\
\hline \multicolumn{6}{|c|}{ Combined data } \\
\hline $\begin{array}{l}\text { Simultaneous } \\
\text { (2-week recovery) }\end{array}$ & 14 & 86 & 64 & 14 & 14 \\
\hline $\begin{array}{l}\text { Serıal } \\
\quad(2 \text {-week recovery })^{b}\end{array}$ & 16 & 88 & 88 & 56 & 32 \\
\hline$\underline{\chi}^{2}$ & & n.s. & n.s. & .03 & n.s. \\
\hline
\end{tabular}

of the serial ablation males. All the intact and unilaterally ablated males showed bubble, curve, and clasp responses. Prior spawning experience did not affect the probability of bubble, curve, clasp, or spawning.

The effects of telencephalon ablation on nest building were assessed by determining the median latency to the first occurrence of bubble and the mean maximum duration of bubble blowing in any prespawning observation in either postoperative spawning trial (Table 2). For all bilaterally ablated groups, the latency to bubble blowing was significantly greater than for intact males $\left(\chi^{2}=25.4, P<0.001\right)$ or for unilaterally ablated males $\left(\chi^{2}=21.5, P<0.001\right)$. Intact and unilaterally ablated males typically began foam-nest building during the afternoon of the first day of the spawning trial: only 1 of 38 bilaterally ablated males bubbled on the first day. The duration of bubble blowing was also decreased in the bilateral ablates (Table 2). Males which were spawned prior to simultaneous ablation showed a postoperative decrease in bubble $(x=1, P<0.04$, sign test; Siegel, 1956), and the serial ablation males which were spawned prior to the second operation bubbled less as full ablates than when unilaterally 
TABLE 2

Effects of Unilateral and of Simultaneous and Serial Bilateral Telencephalon Ablation on Nest Building

\begin{tabular}{|c|c|c|c|c|c|}
\hline \multirow[t]{2}{*}{ Group } & \multirow{2}{*}{$\begin{array}{r}\text { Median } \\
\text { latency } \\
\text { (days) }\end{array}$} & \multirow{2}{*}{$\begin{array}{l}\text { Mean } \\
\text { duration }^{a} \\
\text { (min) }\end{array}$} & \multicolumn{3}{|c|}{ Nest type $^{b}$} \\
\hline & & & Gathered & Scattered & No nest \\
\hline \multicolumn{6}{|l|}{ Simultaneous } \\
\hline $\begin{array}{l}\text { Not spawned } \\
\text { (2-week recovery) } \\
\text { Spawned }\end{array}$ & 3 & 1.24 & 0 & 100 & 0 \\
\hline (2-week recovery) & 3 & 1.01 & 25 & 38 & 38 \\
\hline \multicolumn{6}{|l|}{ Serial } \\
\hline $\begin{array}{l}\text { Not spawned } \\
\text { (2-week recovery) } \\
\text { Spawned }\end{array}$ & 2 & 2.05 & 0 & 100 & 0 \\
\hline (2-week recovery) & 3 & 2.30 & 12 & 62 & 25 \\
\hline $\begin{array}{l}\text { Simultaneous } \\
\text { (7-week recovery) }\end{array}$ & 2 & 1.32 & 0 & 75 & 25 \\
\hline Unilateral & 1 & 4.67 & 100 & 0 & 0 \\
\hline Intact & 1 & 4.83 & 100 & 0 & 0 \\
\hline
\end{tabular}

${ }^{a}$ The maximum duration of bubble in a prespawning observation.

${ }^{b}$ Percentage of males in the group.

ablated $(x=1, P<0.04)$. Although the maximum duration of bubble blowing appeared to be greater for the serial ablates than for the simultaneous ablates, the difference was not significant.

Following complete removal of the telencephalon, most of the males built foam nests in at least one of the spawning trials. However, few of the nests were cohesive, and most were scattered. In a cohesive nest, bubble blowing occurred in one area and resulted in a single organized nest. A scattered nest consisted of isolated clusters of bubbles dispersed in all directions. Bilaterally ablated males built scattered nests $74 \%$ of the time (Table 2). Intact and unilaterally ablated males built only cohesive nests.

Egg eating was common in the bilaterally ablated males; eight of the nine males which spawned ate their eggs. One male ate the eggs in the first spawning trial but not in the second. The eggs of the surviving brood developed into eyed embryos, indicating that sperm release and fertilization had occurred. Whether the other males released sperm was not determined. The intact and unilaterally ablated males were not observed to eat eggs.

To determine whether nonsexual social behavior was affected by the lesions, data collected prior to the occurrence of the first curve response were compiled separately (Table 3). Two-way analyses of variance showed that neither prior spawning nor serial ablation affected approach, display, or attack frequencies. Repeated-measures $t$ tests were used to contrast the behavior of intact males with the behavior of the same males 
TABLE 3

Effect on Nonsexual Social Behavior of Unilateral and of Serial and Simultaneous Bilateral Telencephalon Ablation during the First and Second Spawning Trials ${ }^{a}$

\begin{tabular}{|c|c|c|c|c|c|c|c|c|}
\hline \multirow[t]{3}{*}{ Group } & \multicolumn{8}{|c|}{ Behavior $^{b}$} \\
\hline & \multicolumn{2}{|c|}{ Approach } & \multicolumn{2}{|c|}{$\mathrm{LD}$} & \multicolumn{2}{|c|}{ FD } & \multicolumn{2}{|c|}{ Attack } \\
\hline & 1 & 2 & 1 & 2 & 1 & 2 & 1 & 2 \\
\hline $\begin{array}{l}\text { Simultaneous } \\
\text { Not spawned } \\
\text { (2-week recovery) } \\
\text { Spawned }\end{array}$ & 6.4 & 7.1 & 5.7 & 5.5 & 2.2 & 1.4 & 1.5 & 0.4 \\
\hline (2-week recovery) & 6.4 & 6.2 & 4.2 & 9.9 & 1.6 & 3.8 & 0.3 & 0.5 \\
\hline $\begin{array}{l}\text { Serial } \\
\text { Not spawned } \\
\text { (2-week recovery) } \\
\text { Spawned }\end{array}$ & 6.1 & 6.3 & 5.6 & 9.8 & 1.6 & 3.2 & 0.5 & 0.4 \\
\hline (2-week recovery) & 8.5 & 7.8 & 5.5 & 7.0 & 2.2 & 2.2 & 0.4 & 0.2 \\
\hline $\begin{array}{l}\text { Simultaneous } \\
\text { (7-week recovery) }\end{array}$ & 7.0 & 5.6 & 4.8 & 5.0 & 1.3 & 0.5 & 0.8 & 0.3 \\
\hline Unilateral ablation & 5.2 & & 5.9 & & 4.0 & & 1.1 & \\
\hline Intact & 3.6 & & 7.5 & & 3.3 & & 0.4 & \\
\hline
\end{tabular}

${ }^{a}$ Data collected after the occurrence of the first curve response were excluded.

${ }^{b}$ (1 and 2) First and second trials.

following simultaneous ablation; the latter are designated as the simultaneous spawned 2-week group. The same $t$ test was used to contrast the behavior of unilaterally ablated males with the behavior of the same males following the second unilateral ablation; the latter males are designated as the serial spawned 2-week group. The analyses revealed that bilateral ablation had no effect on display frequencies, and that approach frequency increased following full ablation in both groups $(t=4.0,6.3 ; P<$ $0.006,0.001$ ).

Histological examination revealed that aspiration of the hemispheres of the telencephalon damaged the rostral area of the preoptic nucleus to a varying extent. The nucleus preopticus periventricularis (NPP) and a portion of the nucleus preopticus pars parvocellularis (NPOp) were lesioned in the most extreme case. In no instance did the ablation extend to the pars magnocellularis. Individual differences in the effects of the ablation on reproductive behavior were not correlated with the amount of tissue removed from the preoptic nucleus (Fig. 1).

\section{DISCUSSION}

The behavioral effects of serial and simultaneous ablation of the telencephalic hemispheres were indistinguishable when recovery time following the simultaneous ablation was equal to the interval following the first 
unilateral ablation in the serial ablation procedure. When the period of recovery was equal to the interval following the second unilateral ablation, the simultaneous ablation males showed less sexual behavior than did the serial ablation males. Thus, removal of one lobe of the telencephalon appears to initiate alterations in nontelencephalic structures which result in some apparent savings in sexual behavior following subsequent total ablation. The partial recovery of reproductive functions in simultaneous ablation males may be a result of the occurrence of similar neural alterations. While several mechanisms, such as axonal sprouting and denervation supersensitivity, have been proposed to explain recovery of function following brain damage (Finger et al., 1973), we cannot distinguish between these hypotheses on the basis of our data.

Preoperative spawning experience did not affect postoperative spawning performance. However, since the males arrive in our laboratory as mature adults, we cannot rule out the possibility that some males may have spawned previously. In our experience, Macropodus rarely spawn in crowded holding tanks.

In contrast to previous experiments with Macropodus, most of the bilaterally ablated males in this study showed some components of reproductive behavior. In two of the previous investigations the postoperative recovery period varied from 1 to 3 weeks (Davis et al., 1976a; Schwagmeyer et al., 1977); in a third experiment, a 7-week recovery period was given (Kassel et al., 1976). We had postulated that the longer postoperative interval would result in recovery of reproductive behavior, but no recovery occurred. The hypothesis was upheld by the males in the present experiment. The basis of the increased frequency of reproductive behavior compared to the earlier investigations is not clear. The females in this experiment were noticeably more receptive than those used in the previous experiments, showing high intensity prespawning behavior toward the male. We surmise that the behavior of the female is a potent determinant of reproductive behavior in the telencephalon ablated male.

Over $80 \%$ of the males showed bubble behavior in at least one of the two spawning trials. However, of those males which showed bubbling, almost $90 \%$ failed to build a cohesive nest. This finding is reminiscent of Segaar's (1961) report that telencephalon ablated Gasterosteus aculeatus, a substrate nest builder, dug many small unlocalized holes. It was our impression that bilaterally ablated Macropodus tended to blow bubbles mainly when interacting with a receptive female. The females seemed to elicit bubble-blowing behavior in ablated males with waggle-dance and bite-butt behaviors. The long latency to perform bubble behavior and the decrease in bubble-blowing duration also suggest that the bilateral ablation impairs the activation of nest building.

Intact Macropodus males rarely eat their eggs. The high frequency of egg eating in the ablated males indicates that aspects of parental behavior 
in addition to nest building are under the control of the telencephalon. Aronson (1948) found that male cichlids, Tilapia macrocephala, which brood young in the mouth, fail to incubate eggs following removal of the telencephalon.

Most of the bilateral ablates showed the curve posture that typically precedes clasping. As with bubble blowing, curve seemed to be elicited by persistent waggle-dance and bite-butt behaviors by the female. More than $85 \%$ of the males which were tested 2 weeks following simultaneous telencephalon ablation performed curve but not clasp. These males terminated a curve by a strong sidewise body thrust, and then attacked and chased the female. When clasp did occur, it was often disorganized. Incomplete clasping was seen in both the serial and the simultaneous ablation groups.

The lack of a clear suppression of nonsexual social behaviors early in the spawning trial in bilaterally ablated males is consistent with Aronson's (1948) results for Tilapia. Spawning and related behaviors were decreased in Tilapia males, but social behaviors early in the trial which were not explicitly sexual were not impaired. In Macropodus, approach, attack, and lateral and frontal display occur in unisexual and bisexual encounters and are thus not exclusively sexual. The decreased frequencies of sexual behaviors cannot readily be attributed to lowered nonspecific arousal, contrary to the suggestion of Aronson (1970), since the frequencies of other social behaviors are unchanged. The decrease in sexual behavior may result from an impairment of the male's capacity to perceive sexual stimuli. Telencephalon ablated male cichlids, Hemihaplochromis philander, court males and females, as though they do not distinguish sexual stimuli (Ribbink, 1972). In Macropodus, olfaction is not necessary for sexual behavior (Schwagmeyer et al., 1977), but the possibility that vision and other sensory processes are disrupted cannot be ruled out.

The basic components of male sexual behavior in Macropodus, including curve, clasp, sperm release, nest building, and egg care, are variously decreased following removal of the telencephalon, but none are completely eliminated. This suggests that telencephalic structures are not responsible for the organization of behavior at the level of gross behavioral units. However, the telencephalon may function in the organization of the details of individual behavioral units and in the coordination and integration of units into functional sequences. For example, ablated male Macropodus release bubbles near the surface as intact males do when nest building, but the bubbles are distributed haphazardly. In performing the clasp response, ablated males frequently released the female before fully inverting her; also, while inverting the female, some males rotated full circle and immediately released her, suggesting an impairment of the coordination of this unit of sexual behavior. In addition to its possible role in the integration and coordination of behavior, we propose 
that the telencephalon specifically facilitates the activation of reproductive behaviors. This function presumably depends in part upon neural connections with hypothalamic structures.

The decrease in reproductive behavior may be due to an impairment of the function of the preoptic nucleus. Lesions of the preoptic nucleus can block the chemical elicitation of the spawning reflex in isolated male or female killifish, Fundulus heteroclitus (Macey et al., 1974). Electrical stimulation of the preoptic area elicits sociosexual behavior in freeswimming Lepomis macrochirus (Demski and Knigge, 1971) and sperm release in anesthetized $L$. cyanellus (Demski et al., 1975). Telencephalon ablation in our experiment resulted in varying amounts of destruction of the preoptic nucleus. However, the magnitude of the behavioral deficit did not vary with the amount of preoptic tissue removed. For example, a male that showed curve, clasp, bubble, and egg-care behaviors had extensive damage to NPP and NPOp, while other males with less preoptic damage showed no reproductive behavior. Brain cells in the ventral telencephalon, immediately rostral to the preoptic nucleus and the anterior commissure, concentrate sex steroids (Davis et al., 1976b), and the removal of these cells may contribute to the impairment in reproductive behavior.

\section{REFERENCES}

Aronson, L. R. (1948). Problems in the behavior and physiology of a species of African mouthbreeding fish. Trans. N.Y. Acad. Sci. 2, 33-42.

Aronson, L. R. (1970). Functional evolution of the forebrain in lower vertebrates. In L. R. Aronson, E. Tobach, D. S. Lehrman, and J. S. Rosenblatt (Eds.), "Development and Evolution of Behavior: Essays in Memory of T. C. Schneirla," pp. 75-107. San Francisco: W. H. Freeman.

Davis, R. E., and Kassel, J. (1975). The ontogeny of agonistic behavior and the onset of sexual maturation in the paradise fish. Macropodus opercularis (Linnaeus). Behav. Biol. 14, 31-39.

Davis, R. E., Kassel, J., and Schwagmeyer, P. (1976a). Telencephalic lesions and behavior in the teleost, Macropodus opercularis: Reproduction, startle reaction, and operant behavior in the male. Behav. Biol. 18, 165-177.

Davis, R. E., Morrell, J., and Pfaff, D. W. (1976b). Steroid concentrating cells in the brain of the paradise fish: Autoradiographic localization. Neurosci. Abstr. 2, 650.

Demski, L. S., Bauer, D. H., and Gerald, J. W. (1975). Sperm release evoked by electrical stimulation of the fish brain: A functional anatomical study.J. Exp. Zool. 191, 215-232.

Demski, L. S., and Knigge, K. M. (1971). The telencephalon and hypothalamus of the bluegill (Lepomis macrochirus): Evoked feeding, aggressive and reproductive behavior with representative frontal sections. J. Comp. Neurol. 143, 1-16.

Finger, S., Walbran, B., and Stein, D. G. (1973). Brain damage and behavioral recovery: Serial lesion phenomena. Brain Res, 63, 1-18.

Kassel, J., Davis, R. E., and Schwagmeyer, P. (1976). Telencephalic lesions and behavior in the teleost, Macropodus opercularis: Further analysis of reproductive and operant behavior in the male, Behav. Biol. 18, 179-188.

Macey, M. J., Pickford, G., and Peter, R. E. (1974). Forebrain localization of the spawning 
reflex response to exogenous neurohypophysial hormones in the killifish, Fundulus heteroclitus. J. Exp. Zool. 190, 269-280.

Ribbink, A. J. (1972). The behaviour and brain function of the cichlid fish, Hemihaplochromis philander. Zool. Afr. 7, 21-41.

Rowe, F. A., and Smith, W. E. (1973). Simultaneous and successive olfactory bulb removal: Influences on the mating behavior of male mice. Physiol. Behav. 10, 443-449.

Schwagmeyer, P., Davis, R. E., and Kassel, J. (1977). Telencephalic lesions and behavior in the teleost, Macropodus opercularis: Effects of telencephalon and olfactory bulb ablation on spawning and foamnest building. Behav. Biol. 20, 463-470.

Segaar, J. (1961). Telencephalon and behaviour in Gasterosteus aculeatus. Behaviour 18, 256-287.

Siegel, S. (1956). "Nonparametric Statistics for the Behavioral Sciences." New York: McGraw-Hill.

Winans, S. S., and Powers, J. B. (1974). Neonatal and two-stage olfactory bulbectomy: Effects on male hamster sexual behavior. Behav. Biol. 10, 461-471. 